\title{
Gut and mesenteric lymph node involvement in pediatric patients infected with human immunodeficiency virus
}

This article was published in the following Dove Press journal:

HIVIAIDS - Research and Palliative Care

8 May 2014

Number of times this article has been viewed

\author{
Cecilia Mantegazza' \\ Giovanni Maconi² \\ Vania Giacomet ${ }^{1}$ \\ Federica Furfaro ${ }^{2}$ \\ Chiara Mameli' \\ Cristina Bezzio ${ }^{2}$ \\ Michela Monteleone ${ }^{2}$ \\ Giulia Ramponi' \\ Gian Vincenzo Zuccotti' \\ 'Department of Paediatrics, \\ ${ }^{2}$ Gastroenterology Unit, L Sacco \\ University Hospital, Milan, Italy
}

Correspondence: Cecilia Mantegazza Department of Paediatrics, L Sacco University Hospital, Via Giovanni Battista Grassi, 74, 20157 Milan, Italy

Tel +390239042268

Fax +390239042254

Email cecimante@hotmail.com
Background: The gastrointestinal tract is a primary target for human immunodeficiency virus (HIV). HIV infection causes a depletion of CD4+ T-lymphocytes in gut-associated lymphoid tissue and affects gastrointestinal mucosal integrity and permeability. The gastrointestinal tract has also been suggested as the main reservoir of HIV despite highly active antiretroviral therapy (HAART). We performed a prospective case-control study to assess gut involvement in HIV-infected patients, either naïve or on HAART, using noninvasive methods such as bowel ultrasound and fecal calprotectin.

Methods: Thirty HIV-infected children and youth underwent the following tests: CD4+ T-cell count and HIV viral load, fecal calprotectin, and bowel ultrasound, with the latter evaluating bowel wall thickness and mesenteric lymph nodes. Fecal calprotectin and bowel ultrasound were also assessed in 30 healthy controls matched for age and sex. Fecal calprotectin was measured using a quantitative immunochromatographic point-of-care test, and concentrations ranging from 0 to $200 \mu \mathrm{g} / \mathrm{g}$ were considered to be normal reference values in children.

Results: Fecal calprotectin was normal in 29 HIV-infected patients and was not significantly different from controls (mean values $63.8 \pm 42.5 \mu \mathrm{g} / \mathrm{g}$ and $68.3 \pm 40.5 \mu \mathrm{g} / \mathrm{g}$, respectively; $P=0.419$ ), and did not correlate with HIV viral load, CD4+ T-cell absolute count and percentage, or HAART treatment. No significant changes were found on bowel ultrasound except for enlarged mesenteric lymph nodes, which were observed in seven HIV-infected patients (23.3\%) and two controls $(6.6 \%)$. This finding was significantly correlated with high HIV viral load $(P=0.001)$ and low CD4+ T-cell percentage $(P=0.004)$.

Conclusion: HIV-infected children did not have significant biochemical or ultrasonographic signs of bowel inflammation. A few patients showed enlarged mesenteric lymph nodes, which correlated with uncontrolled HIV infection.

Keywords: children, human immunodeficiency virus, fecal calprotectin, bowel ultrasound

\section{Introduction}

The gastrointestinal tract is a primary target organ for human immunodeficiency virus (HIV). ${ }^{1-3}$ The virus predominantly replicates in CD4+ T-cells in lymphoid tissues, and the gastrointestinal tract contains up to $70 \%-90 \%$ of all lymphocytes in the body. ${ }^{1-3}$

HIV infection causes a rapid and marked depletion of CD4+ T-lymphocytes in gutassociated lymphoid tissues, and alters mucosal integrity and intestinal permeability, even in the absence of opportunistic infections. ${ }^{1-4}$ Such damage may occur acutely after primary infection as well as chronically, ${ }^{2}$ and develops without changes in clinical or immunologic status. HIV itself, via virus-encoded proteins and host-derived molecules, can be the direct cause of such enteropathy, ${ }^{5-7}$ manifesting as "frosted mucosa" in HIV-naïve patients. Histopathologic alterations include villous blunting 
and widening, vacuolated enterocytes, and increased inflammatory cells in the lamina propria. ${ }^{1,2,8}$ Even during therapy, gut-associated lymphoid tissues show increase levels of local inflammation and immune activation, probably due to incomplete viral suppression.

Beyond being involved in HIV enteropathy, the gastrointestinal tract is suggested to be the main reservoir of HIV despite highly active antiretroviral therapy (HAART). ${ }^{9,10}$ Studies in successfully treated simian immunodeficiency virus-infected rhesus macaques, the only suitable model for investigation, have suggested the gastrointestinal tract to be the largest viral reservoir. ${ }^{11-13}$ Hoorike et al showed that lymphatic tissues act as the anatomic compartment for virus replication during antiretroviral therapy. ${ }^{11}$ Estaquier et al examined different lymphoid organs and found that the mesenteric ganglia may be the main reservoir of the virus. $^{12,13}$

Currently, it is possible to perform a noninvasive assessment of inflammation in the gut using fecal calprotectin and bowel ultrasound. High levels of fecal calprotectin, a calciumbinding and zinc-binding protein, abundant in neutrophils and found in monocytes/macrophages, correlate strongly with mucosal inflammation of the gut. ${ }^{2,14,15}$ Recent studies have demonstrated a rise in fecal calprotectin in untreated HIV-infected children. Gori et al found high levels of fecal calprotectin in 27 of 53 HIV-naïve patients, ${ }^{3}$ and Hestvik et al showed a median fecal calprotectin concentration above the reference value in HIV-infected, HAART-naïve children in Uganda. ${ }^{15}$ Bowel ultrasound is a well-established method for assessment of direct and indirect signs of gut inflammation, such as increased wall thickness, mesenteric hypertrophy, and enlarged mesenteric lymph nodes, in inflammatory bowel disease. ${ }^{16}$ To the authors' knowledge, no study has used bowel ultrasound to evaluate gut involvement in HIVinfected children.

To date, limited data are available on HIV gut enteropathy and no studies could be found that specifically investigated inflammatory changes in the gut in HIV-infected untreated and treated pediatric patients. Therefore, we performed a prospective case-control study aiming to assess gut involvement in HIV-infected pediatric patients, either naïve or on HAART, using noninvasive methods, ie, fecal calprotectin and bowel ultrasound.

\section{Materials and methods}

This was a prospective case-control study performed in HAART-treated or HAART-naive children and youth with HIV infection. The study was approved by the ethics committee at L Sacco Hospital, and informed consent was obtained from the parents or legal guardians of the patients.

\section{Patients}

A series of consecutive unselected HIV-infected subjects (aged 16-260 months) regularly followed in the Infectious Disease Clinic at the Department of Paediatrics, L Sacco Hospital, a tertiary hospital in Milan, were enrolled from January to July 2012. Patients were included irrespective of the mode of HIV infection (vertical or horizontal), and of their treatment status (naïve or on HAART).

Patients with a relevant current or recent history of gastrointestinal symptoms (eg, abdominal pain, changes in bowel movements, bloating, or dyspepsia), concomitant opportunistic infections, or organic gastrointestinal disease (eg, celiac disease, food allergy) were excluded after appropriate diagnostic workup, which included an accurate history and the following analyses: stool cultures for Salmonella, Shigella, and Campylobacter bacteria, search on feces for Rotavirus and Norovirus antigens, search for parasites, antiendomysial and antitransglutaminase antibody titers, and total immunoglobulin $\mathrm{E}$ antibodies. Thirty healthy subjects matched by age ( \pm 6 months) and sex were also enrolled as controls.

\section{Methods}

Eligible HIV-infected patients underwent tests for CD4+ T-cell count and HIV viral load on the same day. Both HIVinfected patients and controls underwent fecal calprotectin assessment and bowel ultrasound.

\section{CD4+ T-cell count and HIV viral load}

Fresh blood samples were collected to measure CD4+ T-cell absolute count and percentage using single-platform flow cytometry. Three directly labeled monoclonal antibodies in two different combinations were used (CD3/ CD19/CD16 and CD3/CD4/CD8). Fluorescence of leukocytes was measured using a Cytotron ${ }^{\circledR}$ absolute flow cytometer (Ortho Cytometry, Raritan, NJ, USA). Immunocount II software was used for analysis of the acquired data (UK National External Quality Assessment Service, Watford, UK). The laboratory of immune hematology took part in the UK National External Quality Assessment Service programs for standardization of immune phenotyping methods. HIV viral load was measured using Quantiplex (bDNA) assay version 3.0 with a lower limit of detection of 37 copies per mL (Bayer Diagnostics, Norwood, MA, USA). 


\section{Fecal calprotectin}

A sample of feces for calprotectin assay was measured using a quantitative immunochromatographic point-of-care test (Buhlmann Laboratories AG, Schonenbuch, Switzerland). Stool specimens were analyzed after extraction using a commercial fecal sample preparation device (Roche Diagnostics GmbH, Mannheim, Germany). Fecal calprotectin was measured in fresh samples by the Quantum blue point-ofcare test, which is a sandwich-type quantitative immunochromatographic test in which two monoclonal antibodies specifically bind to fecal calprotectin. The detection antibody is conjugated to gold colloids that appear on the test cartridge as a purple band with color intensity proportional to the calprotectin concentration. Signal intensities were measured by a dedicated reader using a lot-specific calibration curve to calculate calprotectin concentrations. The limit of detection of the assay is $30 \mu \mathrm{g} / \mathrm{g}$ stool, and the linearity is up to $300 \mu \mathrm{g} / \mathrm{g}$ stool. Fecal extracts showing values $>300 \mu \mathrm{g} / \mathrm{g}$ stool were diluted with extraction up to 1:5, so that the upper limit value of the test was $1,500 \mu \mathrm{g} / \mathrm{g}$ stool. Calprotectin concentrations in the range of $0-200 \mu \mathrm{g} / \mathrm{g}$ were considered to be normal reference values for children..$^{14,17}$

\section{Bowel ultrasound}

The same ultrasonographer (GM, with a mean bowel ultrasound experience of $>30,000$ examinations, who performed a mean of 2,000 ultrasound examinations per year) performed the ultrasound scans. All examinations were performed on a Logos Hi-Vision C machine (Hitachi Medical Systems, Tokyo, Japan) using a broadband convex transducer (frequency $3.5-5 \mathrm{mHz}$ ) for the first evaluation and then a microconvex transducer (frequency 4-8 $\mathrm{mHz}$ ) for a detailed evaluation of the bowel, lymph nodes, and mesentery. The following ultrasound parameters were evaluated: bowel wall thickness (normal $\leq 2 \mathrm{~mm}$ ) ${ }^{18}$ small bowel dilatation (normal $<25 \mathrm{~mm}$ ), ${ }^{19}$ free fluid within the peritoneal cavity, enlarged mesenteric lymph nodes (short axis $>8 \mathrm{~mm}$ ) ${ }^{20}$ enlarged vermiform appendix (diameter $>6 \mathrm{~mm}$ ), and mesenteric hypertrophy (presence of hyperechoic area around thickened bowel wall $>5 \mathrm{~mm}$ ). ${ }^{21,22}$ All patients were examined in the morning after fasting for at least 6 hours with an empty or moderately replete bladder.

\section{Statistical analysis}

Continuous variables were expressed as the mean and standard deviation. The Mann-Whitney $U$ test, Student's $t$-test, and Fisher's exact test were used to compare continuous and categorical variables as appropriate. A $P$-value $<0.05$ was considered to be statistically significant.

\section{Results}

Thirty HIV patients were enrolled consecutively. None was excluded on the basis of a positive history for gastrointestinal symptoms or altered laboratory tests. The demographic and clinical characteristics of the HIV patients and controls are shown in Tables 1 and 2. Seven patients were not on antiretroviral therapy; 23 patients were on HAART including two nucleoside analogue reverse transcriptase inhibitors in combination with either a protease inhibitor or a non-nucleoside reverse transcriptase inhibitor.

In all HIV-infected patients, fecal calprotectin was normal (mean value $63.8 \pm 42.5 \mu \mathrm{g} / \mathrm{g}$; upper normal value $200 \mu \mathrm{g} / \mathrm{g}$ ) except in one, who had a calprotectin level of $205 \mu \mathrm{g} / \mathrm{g}$. This child had an HIV-RNA of 892 copies per mL, a CD4+ T-cell absolute count of $440 / \mathrm{mm}^{3}$, and a CD4+ T-cell percentage of $24.2 \%$, and was not on HAART. Fecal calprotectin in the HIV patients was not significantly different from that in controls (mean value $68.3 \pm 40.5 \mu \mathrm{g} / \mathrm{g} ; P=0.419$ ).

Fecal calprotectin did not correlate significantly with HIV-RNA $(P=0.704), \mathrm{CD} 4+\mathrm{T}$ cell absolute count $(P=0.134)$ or percentage $(P=0.994)$, or current HAART treatment $(P=0.493)$. In subjects with an undetectable viral load (HIV RNA $<37$ copies per $\mathrm{mL}$ ), fecal calprotectin was not significantly different from that in individuals with a higher viral load. Likewise, these patients did not differ with regard to mean CD4+ T-cell absolute count or percentage (Table 3).

None of the HIV patients showed significant changes on bowel ultrasound, except for enlarged mesenteric lymph nodes found in seven patients $(23.3 \%)$, mainly at the mesenteric root, the right iliac fossa, and periappendicular area. Only two $(6.6 \%)$ healthy subjects showed enlarged

Table I Demographic and clinical features of HIV patients

\begin{tabular}{|c|c|c|}
\hline Characteristics & Mean, SD & Number (\%) \\
\hline Age, months & 133,5 & \\
\hline Females & & 17 (56.7\%) \\
\hline \multicolumn{3}{|l|}{ Ethnicity } \\
\hline Caucasian & & $23(76.7 \%)$ \\
\hline African & & 7 (23.3\%) \\
\hline Age at diagnosis, months & 24,3 & \\
\hline Children on HAART & & $23(76.6 \%)$ \\
\hline Exposure to HAART, months & $40.6,47$ & \\
\hline Children with HIV-RNA $<37 \mathrm{cp} / \mathrm{mL}$ & & $17(56.6 \%)$ \\
\hline HIV-RNA in $\mathrm{cp} / \mathrm{mL}$ & $7,629,18,456$ & \\
\hline CD4+ T-cell absolute count $/ \mathrm{mm}^{3}$ & $746.3,443.8$ & \\
\hline CD4+ T-cell \% & $29.8,8.7$ & \\
\hline
\end{tabular}

Abbreviations: HIV, human immunodeficiency virus; SD, standard deviation; HAART, highly active antiretroviral therapy. 
Table 2 Demographic and clinical features of healthy controls

\begin{tabular}{lll}
\hline Characteristics & Mean, SD & Number (\%) \\
\hline Age, months & 135,5 & \\
Females & & $17(56.7 \%)$ \\
Ethnicity & & \\
$\quad$ Caucasian & & $25(83.3 \%)$ \\
African & & $5(16.7 \%)$ \\
\hline
\end{tabular}

Abbreviation: SD, standard deviation.

lymph nodes. The lymph nodes had a normal structure and vascularization in all patients and controls.

Patients with enlarged lymph nodes showed HIVRNA levels significantly higher than those in patients without mesenteric lymph nodes $(P=0.001)$ and a lower CD4+ T-cell percentage ( $P=0.004$, Table 4). However, the prevalence of enlarged lymph nodes in patients with a viral load $>37$ copies per $\mathrm{mL}$ was higher, but was not significantly different from that in those with an undetectable viral load ( $5 / 12$ versus $2 / 18 ; P=0.084)$. No statistically significant correlation was found between the presence of enlarged lymph nodes and fecal calprotectin levels $(P=0.921)$ or CD4+ T-cell absolute count $(P=0.564)$. An enlarged vermiform appendix was found in three patients, all of whom also had enlarged mesenteric lymph nodes and two of whom had an HIV viral load $>37$ copies per $\mathrm{mL}$.

\section{Discussion}

As far as we are aware, this is the first study to investigate mucosal inflammation in pediatric HIV-infected patients, either naïve or on HAART, using noninvasive tests including fecal calprotectin and bowel ultrasound. HIV-positive subjects, either with detectable or undetectable viral load, did not show a rise in fecal calprotectin or any signs of inflammation on bowel ultrasound. Further, no significant correlation with HAART was found. However, we did find enlarged lymph nodes in $23 \%$ of our patients, suggesting that the gastrointestinal tract may be a reservoir of HIV despite HAART and that mesenteric lymph nodes may be primarily involved in this process.

Table 3 Comparison of HIV-infected patients on the basis of viral load

\begin{tabular}{llll}
\hline & $\begin{array}{l}\text { HIV-RNA } \\
<\mathbf{3 7} \mathbf{~ c p / m L} \\
(\mathbf{n = 1 8 )}\end{array}$ & $\begin{array}{l}\text { HIV-RNA } \\
\mathbf{3} \mathbf{3 7} \mathbf{~ c p / m L} \\
\mathbf{( n = 1 2 )}\end{array}$ & P-value \\
\hline $\begin{array}{l}\text { Fecal calprotectin } \mu \mathrm{g} / \mathrm{g} \\
\text { (mean, SD) }\end{array}$ & $63.2,39.3$ & $65.3,48.8$ & 0.884 \\
$\begin{array}{l}\text { CD4+ T-cell absolute } \\
\text { count/mm } \text { (mean, SD) }^{3}\end{array}$ & $798.8,446 . \mathrm{I}$ & $667.4,447.5$ & 0.438 \\
$\begin{array}{l}\text { CD4+ T-cell \% (mean, SD) } \\
\text { Abbreviation: SD, standard deviation; HIV, human immunodeficiency virus. }\end{array}$ & $31.9,6.4$ & $26.5,10.8$ & 0.138 \\
\hline
\end{tabular}

Table 4 Comparison between patients on the basis of lymph nodes size

\begin{tabular}{|c|c|c|c|}
\hline & $\begin{array}{l}\text { Lymph nodes } \\
>8 \mathrm{~mm} \\
(\mathrm{n}=7)\end{array}$ & $\begin{array}{l}\text { Normal } \\
\text { lymph nodes } \\
(n=23)\end{array}$ & $P$-value \\
\hline $\begin{array}{l}\text { Fecal calprotectin }(\mu g / g) \\
(m e a n, S D)\end{array}$ & $65.429,48.442$ & $63.348,41.818$ & 0.921 \\
\hline $\begin{array}{l}\text { HIV-RNA }(\mathrm{cp} / \mathrm{mL}) \\
\text { (mean, SD) }\end{array}$ & $29.605,29.682$ & $911,2.892$ & 0.001 \\
\hline $\begin{array}{l}\text { CD4+ T-cell absolute } \\
\text { count } / \mathrm{mm}^{3} \text { (mean, SD) }\end{array}$ & $659.00,655.81$ & $772.83,373.04$ & 0.564 \\
\hline CD4+ T-cell \% (mean, SD) & 2I.87I, II.072 & $32.170,6.437$ & 0.004 \\
\hline
\end{tabular}

Abbreviation: SD, standard deviation.

Our results differ from those of Gori et al who found high levels of fecal calprotectin in 27 of 53 HIV-naïve patients, and from those of Hestvik et al who reported a median fecal calprotectin concentration above the reference value in HIVinfected HAART-naïve children in Uganda. ${ }^{3,15}$ Hestvik et al also demonstrated increased fecal calprotectin concentration in children with more advanced disease. ${ }^{15}$ However, both of these studies considered only HIV HAART-naïve patients, did not take into account whether their patients had symptoms of organic disease, and did not exclude other causes of inflammation by fecal or blood analysis. Whereas Gori et al and Hestvik et al used a calprotectin enzyme-linked immunosorbent assay with a normal reference value of $50 \mu \mathrm{g} / \mathrm{g}, 3,15 \mathrm{we}$ used a quantitative point-of-care test (Buhlmann Laboratories AG); a recent study comparing this test with the more widely used enzyme-linked immunosorbent assay recommended a normal reference value of $200 \mu \mathrm{g} / \mathrm{g}$ in children, regardless of age. ${ }^{14,17}$ Even though our method is not standardized, the negative value for fecal calprotectin in the control group and its comparability with that found in HIV-infected patients reinforces our results.

Several studies suggest that abnormal immune activation as one of the principal factors associated with progression of HIV disease. Persistent inflammation and immune activation in spite of suppressive HAART have been proposed to be the most important factors preventing the restoration of normal health in HIV-infected individuals. ${ }^{23}$ Many have speculated that chronic activation results from a damaged bowel mucosal barrier and stimulation of immune cells by microbial products. We did not confirm a rise in fecal calprotectin in our HIV-infected patients, either naïve or on HAART, and did not find direct sonographic signs of mucosal inflammation in the gut. However, this study has two major weaknesses, ie, a limited sample size, which may have limited its statistical power, and lack of inclusion of an invasive method for direct assessment of the mucosa. 
Therefore, further studies are required to confirm the results of our present study.

Despite the absence of indirect signs of gastrointestinal mucosal inflammation and the normal appearance of the small bowel, colon, and appendix, we found enlarged lymph nodes in $23 \%$ of our patients. Lymph node enlargement correlated with a higher HIV load and a lower CD4+ T-cell percentage, but not with fecal calprotectin. These findings suggest that the gastrointestinal tract is not only involved in HIV enteropathy, but may also be a reservoir of HIV despite HAART, and that mesenteric lymph nodes may be primarily involved in this process.

HAART is currently the only therapeutic option available for HIV-infected individuals. Unfortunately HAART is not completely successful because the viral load rebounds to pretreatment levels when treatment is stopped. ${ }^{14}$ Palmer et al suggested ongoing viral replication in patients with HAARTcontrolled viremia. ${ }^{24}$ Therefore, HIV may persist in viral reservoirs during therapy, and there might be specific cell types that allow its replication during HAART. ${ }^{3}$ Eradicating viral reservoirs is the only way to achieve a complete resolution of HIV-1 infection.

Two studies in simian immunodeficiency virus-infected rhesus monkeys have demonstrated that lymphatic tissues act as the anatomic compartment for active viral replication during antiretroviral therapy. In 2008, Estaquier et $\mathrm{al}^{12,13}$ reported a study comparing immunologic and virologic parameters in lymphoid and nonlymphoid organ tissues in both controlled and uncontrolled simian immunodeficiency virus-infected monkeys. According to this study, the virus was predominantly localized in the lymphatic tissues and, considering in particular animals with HIV viral load below 37 copies per mL, in the mesenteric ganglia. Hoorike et $\mathrm{al}^{11}$ found higher levels of viral RNA in both the superior and inferior mesenteric lymph nodes in animals on HAART. ${ }^{12,13}$ Neither of these studies reported lymph node size.

Given that an anatomic study in humans is not ethically possible, the only way to analyze human lymph nodes is to evaluate their structure and size by imaging procedures. We found the presence of enlarged lymph nodes in $23 \%$ of patients, which correlated with HIV-RNA and CD4+ T-cell percentage but not with mucosal inflammation. Although this finding was nonspecific and inconclusive, and must be confirmed in a larger series of patients, it could serve as a hint for further prospective studies assessing whether variation in lymph node size associated with an increase or decrease in HIV viral load has some prognostic value.
In conclusion, asymptomatic HIV-infected children in this study did not have significant biochemical or ultrasonographic signs of bowel inflammation. However, some had enlarged mesenteric lymph nodes, which were correlated with uncontrolled HIV infection. Whether this finding is a sign of a reservoir of HIV despite active antiretroviral therapy and has any prognostic value should be confirmed in larger prospective studies.

\section{Disclosure}

The authors report no conflicts of interest in this work.

\section{References}

1. Dandekar S. Pathogenesis of HIV in the gastrointestinal tract. Curr HIV/AIDS. 2007;4(1):10-15.

2. Brenchley JM, Douek DC. HIV infection and the gastrointestinal immune system. Mucosal Immunol. 2008;1(1):23-30.

3. Gori A, Tincati C, Rizzardini G, et al. Early impairment of gut function and gut flora supporting a role for alteration of gastrointestinal mucosa in human immunodeficiency virus pathogenesis. $J$ Clin Microbiol. 2008;46(2):757-758.

4. Brenchley JM, Douek DC. Microbial translocation across the GI tract. Annu Rev Immunol. 2012;30:149-173.

5. Maingat F, Halloran B, Acharjee S, et al. Inflammation and epithelial cell injury in AIDS enteropathy: involvement of endoplasmic reticulum stress. FASEB J. 2011;25(7):2211-2220.

6. Miller TL, Agostoni C, Duggan C, Guarino A, Manary M, Velasco CA. Gastrointestinal and nutritional complications of human immunodeficiency virus infection. J Pediatr Gastroenterol Nutr. 2008;47(2):247-253.

7. Brenchley JM, Douek DC. The mucosal barrier and immune activation in HIV pathogenesis. Curr Opin HIV AIDS. 2008;3(3):356-361.

8. Pellecchia P, Brandt LJ. Intestinal abnormalities in AIDS. In: Classen M, Tytgat GNJ, Lightdale CJ, editors. Gastroenterological Endoscopy. Stuttgart, Germany: Thieme; 2010.

9. Embretson J, Zupancic M, Ribas JL, et al. Massive covert infection of helper T lymphocyte and macrophages by HIV during the incubation period of AIDS. Nature. 1993;362(6418):359-362.

10. Chun TW, Davey RT Jr, Engel D, Lane HC, Fauci AS. Re-emergence of HIV after stopping therapy. Nature. 1999;401(6756):874-875.

11. Hoorike M, Iwami S, Kodama M, et al. Lymph nodes harbor viral reservoirs that cause rebound of plasma viremia in SIV-infected macaques upon cessation of combined antiretroviral therapy. Virology. 2012;423(2):107-118.

12. Estaquier J, Idziorek T, de Bels F, et al. Programmed cell death and AIDS: significance of T-cell apoptosis in pathogenic and non pathogenic primate lentivirus infections. Proc Natl Acad Sci U SA. 1994;91(20):9431-9435.

13. Estaquier J, Hurtrel B. Sanctuarie du virus di l'immunideficience humaine ed mecanismes d'echappement. [Mesenteric lymph nodes, a sanctuary for the persistance of HIV. Escape mechanisms.] Med Sci (Paris). 2008;24(12):1055-1060.

14. Dolci A, Panteghini M. Comparative study of a new quantitative rapid test with an established ELISA method for faecal calprotectin. Clin Chim Acta. 2012;413(1-2):350-351.

15. Hestvik E, Olafsdottir E, Tylleskar T, et al. Faecal calprotectin in HIVinfected, HAART naïve Ugandan children. $J$ Pediatr Gastroenterol Nutr. 2012;54(6):785-790.

16. Novak KL, Wilson SR. The role of ultrasound in the evaluation of inflammatory bowel disease. Semin Roentgenol. 2013;48(3):224-233.

17. Joshi S, Lewis SJ, Creanor S, Ayling RM. Age-related faecal calprotectin, lactoferrin and tumour M2-PK concentrations in healthy volunteers. Ann Clin Biochem. 2010;47(Pt 3):259-263. 
18. Haber HP, Stern M. Intestinal ultrasonography in children and young adults: bowel wall thickness is age-dependent. J Ultrasound Med. 2010;19(5):315-321.

19. Pallotta N, Baccini F, Corazziari E. Contrast ultrasonography of the normal small bowel. Ultrasound Med Biol. 1999;25(9):1335-1340.

20. Karmazyn B, Werner EA, Rejaie B, Applegate KE. Mesenteric lymph nodes in children: what is normal? Pediatr Radiol. 2005;35(8): 774-777.

21. Rettenbacher T, Hollerweger A, Macheiner P, Gritzmann N. Ultrasonography of the normal vermiform appendix. Ultraschall Med. 1997;18(3):139-142.
22. Maconi G, Greco S, Duca P, et al. Prevalence and clinical significance of sonographic evidence of mesenteric fat alterations in Crohn's disease. Inflamm Bowel Dis. 2008;14(11):1555-1561.

23. Kuller LH, Tracy R, Belloso W, et al. Inflammatory and coagulation biomarkers and mortality in patients with HIV infection. PLoS Med. 2008;5(10):e203.

24. Palmer S, Maldarelli F, Wiegand A, et al. Low level viremia persists for at least 7 years in patients on suppressive antiretroviral therapy. Proc Natl Acad Sci U S A. 2008;105(10):3879-3884.

\section{Publish your work in this journal}

HIV/AIDS - Research and Palliative Care is an international, peerreviewed open-access journal focusing on advances in research in HIV, its clinical progression and management options including antiviral treatment, palliative care and public healthcare policies to control viral spread. The journal welcomes original research, basic science, clinical \& epidemiological studies, reviews \& evaluations, expert opinion \& commentary, case reports \& extended reports. The manuscript management system is completely online and includes a very quick and fair peer-review system. Visit http://www.dovepress.com/ testimonials.php to read real quotes from published authors.

Submit your manuscript here: http://www.dovepress.com/hivaids---research-and-palliative-care-journal 